history ut wauy cases of taty htar, tatty hiver, atd Bright's disease; and where this change does not take place there is danger of iersistent enlargement of the beart. I have trace $x$ many such cases following upon the failure of lactation. In relation to haty and calcareous action, that singular affection, mollities opsium, claims attention. It is a remarkable example of the work of menstruation and gestation which deserves more investigation than it has hitherto received. Here, aga:n, ezperiment comes to our aid. Febling of Basle removed the oraries in nine cases with the object of curing the disease : eight of the cases recovered and the progress of the disease was checked. He noticed unusual vascularity of the appendages, the arteries being enlarged as well as the veins. This natural experiment of gestation has instructive application to the solution of the problem of fatty degeneration in sterile women and even in men. It applies also to calcareous degeneration. In close connexion with this subject I may also call attention to the history of fatty metamorphosis in the placenta first described by me in 1851.3 One remarkable fact in the history of fatty and calcareous degeneration is witnessed in the deposit of calcareous matter in the placenta, not necessarily as a result of disease, but rather of excessive, perhaps conservative, physiological action. The study of this condition supplies an important link in the history of calcareous deposits in the heart and bloodressels. In prequancy it is seen not only in the placenta, but also in the craniam. Rokitansky (1838) and Ducrest (1844) observed osteophytes or osseous neoplasms, or a tissue recembling bone, outrive the dura mater. This has been verified by many observers, myself amongst the number, since. These concretions suggest the hypothesis that they are a part of the excess of ossific material prepared for the building $u p$ of the foetal skeleton. I have also advanced the opinion that they have some celation to the preparation of milk, in which fluid a considerable proportion of calcareons elements exist. Another lesson suggested by this study is the strong absorption force following on delivery, especially when intensified by bremormage, in the proneness to absorption of any noxious stuff that masy come within the range of the absorbing organs. We are fandiar with the sucking-in of decomposing matter lying in the vterus or vagina, causing septicremia. In like manner observation in hospitals especially has proved bow ge:ms carried in the air may be absorbed by the lnngs, and in this was 3 produce fever. Direct experiment has also shown me hat poison mag be absorbed through the unbroken skin.

Here I way offer an hypothesis, the result of some experience and much thought-that the germs of disease may be inhaled by the lungs or absorbed from the genital canal. It was at one time believed that gestation retarded the progress of puthisis. It may be cocasionally true that phthisis does not make rapid advance during pregnancy, but it is certain, according to my observations, that it makes accelerated grogress from the moment of parturition. How is this? Not only is the circulation invaded by the usual noxious stuif of puerpery and external sources, but it draws in the tuberculous germs lying more or less dormant in the lungs. Recently Dr. A. Guzzoni of Turin (1890) has performed experiments in point. He introduced into the vagina of a guinea-pig a piecs of tuberculous lung of a cow and a little dried powder of phthisical expectoration. The animal prefiented in the left lung a tuberculous nodule, and the fotus showed tubercle in the viscera, lungs, spleen, and liver. The propagation of syphilis is a familar experience. Facts of this kind point forcibly to the control of the absorptice faculty to diminish the risk of absorbing or intensifying disease.

Theraptuticai aprlication of Forces of Gestation.

I have for many years turned the natural and intensified absorption-force to therapentical profit by injecting iodine and other agents into the uterus and vagina. Thus I have seen hyperplasia and hypertrophic enlargements of the aterus dispersed. So active is the absorption process through this route that the whole system is pervaded. The starch test applied to the skin and saliva reveals the permeation of iodine. I confidently believe that this method admits of further ase in the treatment of other than uterine diseases. In many cases it may prove more practicable than subcutaneous injection. Thus we may chase a poison through the system, sending the antidote after it. When considering the profit to be drawn from activn absorption, and the means by which tivis force can be increased, we must not overlook the mexpis of controlling that force in keeping it within

3 Transulions of the Royal Medical and Chirurgical Society. useful limits. Much may be done by supplying the syster with proper nourishment, and sometimes we may fill th vacunm by transfusion.

Another phase in the history of absorption is seen whe this process is carried to excess. Once started it may pas the physiological bound and result in atrophy. Here w are reminded that nature is often deficient in the power $t$ keep her forces within useful limits. Action once started howsoever beneficial in design and character, is apt to rur into extremes. This is seen in hæmorrhage, in arterial tension, in nervous tension, in metabolism-indeed, in all the functions of the body. It is here that the physician steps in to apply those means which enlightened judgment of the forces at work and clinical experience give him to control and guide the natural forces to the execution of their proper office.

And now it is more than time to conclude. Let me resume the main points set forth. The political bearing of the argument tends to show how general and special medical science has suffered from the vicious subdivision of medi. cine into sections represented by special colleges and societies constituted and acting to the neglect of obstetrics and gynæcology. Gestation and menstruation, regarded as a natural experiment, throw the clearest light upon the origin, essence, and treatment of many diseases. These points often elnde the recognition of the physician, and he is thence often driven to false conclusions as to etiology. The observation of the diseases which arise during gestation suggests the bypothesis that the primary or initiative factors of diseases spring from the periphery of the system, and that the action and changes of structure of the central organs and glands are responsive and secondary. The study of pregnancy and puerpery brings before the observer the most striking examples (1) of the working of the great forces of exalted nervous and vascular tension in the pro duction of new tissue: (2) of the converse force of active absorption; (3) of the influence of hæmorrhage; and (4) of blood changes and metabolism. Those who neglect this study are prone to associate disordered function and secretions with special organic change; whilst in trath all may begin with a common cause trying the whole system, the weaker organ breaking down under exaggerated physiological strain. Many of the problems mooted are subjects for inquiry. I do not pretend to have solved them. Enough if I can help to point out one source of light to guide the inquirer. I physiology be the rational basis of pathology, may we not say that gestation-the most prolific source of physiological light -is the surest threshold of medicine? One explanation of, if not an apology for, the neglect by the ordinary physician of what obstetrics can teach may lie in the fact that the opportunities of observation which fall in his way are rare. What is not sought is rarely found or appreciated. The more incumbent is it on the gynæcologist to cultivate in a liberal spirit that source of light in which he moves, and so to help to restore the solidarity of medicine.

Let meagain thank you for the honour conferred upon me by this society. That honour, I feel, is enhanced by the consciousness that this graceful act binds me with you, under the inspiration of the genius loci, to do honour to the memory of William Hunter, by continuing the work of which he is one of the most illustrious architeots.

\section{IS COLLES' LAW A MISNOMER?}

\section{Br GEORGE OGILVIE, B.Sc., M.B. EdIN.} M.R.C.P. LOND.,

PHYSICIAN TO THE HOSPITAI FOR EPILEPSY AND PARATTSIS AN OTHER DISEASES OF THE NERYOUS SYSTEM, REGENT'S PARK, N.T.

THE generally accepted doctrine that the mother of a child that suffers from inherited syphilis cannot contrac syphilis from her own offepring has been known as "Colles law" not only in this country, but by the whole medical world It was first called a "law" by Diday" in the year 1854, and no by Mr. Hutchinson, as has been erroneously stated by $\mathrm{Dr}$ McDonnell, editor of Colles' works. ${ }^{2}$ Having lately hac

1 Traité de la Syphilis des Noureau-nés, p. 286. Paris, 1854. 2 Transactions of the New Sydenbam Society, vol. xcii., p. 288 London, 1881. 
occasion to consult the foreign literature on this subject, I have been surprised to find that by some writers the paternity of this doctrine has been disallowed to Colles and attributed to Baumès, and that this view has been upheld in such wellknown and widely read text-books as those of Fournier ${ }^{3}$ and Kaposi. ${ }^{4}$ Fournier, with some rhetorical effusion, exclaims "Rendons à César ce qui appartient à César," and replaces the name of Colles by that of Baumès. Kaposi, however, contents himself by saying that it is more correct to call it after Baumès ; and Bergh expresses himself in a similar manner. Finding that Colles' book ${ }^{6}$ was published three years before that of Baumès, ${ }^{7}$ and as the meaning of Colles' statement appeared to me to be quite clear and definite, I was interested to find out on what grounds the Continental writers tried to sever his name from this law, the formulating of which must always be regarded as a bigh testimony to his powers as a clinical observer. The perusal of what has been writeten on this matter has convinced me that the alteration introduced by the writers above mentioned is in no way justified, some of Colles' statements having been either misconstrued or misrepresented. I-believe that the following presentation of the arguments adduced by these writers, and the criticism of those arguments, in the light of Colles' original text, will prove their fallacy. I wish it, however, to be understood that in the following remarks the validity of Colles' law is not discussed, but only the history of its origin.

To enable the reader to judge I shall give first of all a short sketch of Colles' own remarks on this subject. They are to be found under the heading: "The Appearance and Nature of those Diseases which are communicated by the Infant to the Nurse," at the end of Chap. xiil. (pp. 283 to 304). Their object (as is clearly seen from the concluding remarks of Chap. i., p. 24) is not to discuss the question of the mother's state of health before and aftex the birth of a syphilitic child, 8 but to prove the infectious nature of the secondary symptoms of the child, and at the same time to show the identity between the disease transmitted by the child to the nurse and that acquired by the parents and transmitted to the child. On these two points, both at the time when Colles wrote and afterwards-in fact, until the conversion of Ricord by Rollet-the teaching of John Hunter was dominant. Colles' object was to disprove the correctness of Hunter's teaching and to prove the identity of the acquired and congenital forms of syphilis. He therefore begins by giving a description of the nurse's disease, which commences at the nipple and is followed by constitutional symptoms. He then remarks that he has never seen the nipple inoculated when the mother was the nurse of the child. He further relates a case which appeared to form an exception to this "curion fact," but which on closer inquiry proved to be a case of syphilis acquired by the child after birth and given to the mother. In commenting on this case he says :-

(a) “As yet I have not seen any instance in which an infant infected by the mother communicated a venereal ulcer of the nipple to her.'"

Returning to his subject he then speaks about the treatment of nurse and child, or nurse alone, by mercury. In the remainder of the chapter he shows how the disease, which has been traced from the parents to the child, and from the infant to the nurse might be communicated by the nurse to her husband, and might also, through secondary symptoms, spread to the dry-nurse or any other person handling the child. ${ }^{9}$ In proof of this he gives three cases, of which the first only at present is of interest. A servant

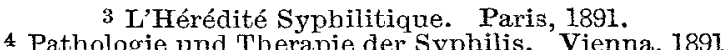

Congenitale Syphilis bei paterner Infection. Unna's Monatshefte für Practische Dermatologie, vol. xvii., No. 3, p. 117.

Mercury. Iondon, 1837.

Mercury. London, 1837

1840. Précis Théorique et Pratique des Maladied

See pp. 264-268.

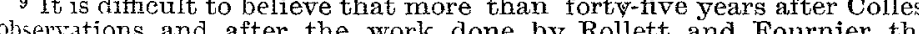
following should and "Dournier, the follow should appear in a text-book of surgery: "Before speaking w on specin Would remark on the absolute necessity of their being suckled and not be infinitel by hand of whom the dister mothor; but in the low classes of soclety, among whom the disease is almost exclusively m this, the sertees of a wet-nurse can hardy be obtained. According incistane poor which prevents the incalculable mischief which might be produced by engaging a healthy edition to suck a syphilic (Diseases of the Eye, by J. Dickson, edited by J.W. Hulke), in the Jear 1893 . girl is infected by a child, both parents of which had syphilis two years before its birth. Here Colles remarks

(b) "And let it be observed that the mother had not in any way suffered from the disease of the child. She bad not received any infection from her own child, yet the disease was capable of infecting the servant girl "' ( $\mathrm{p} .293$ ).

These statements will be referred to in the following remarks as $(a)$ and $(b)$.

The four cases referred to are the only cases given by Colles-i.e., the first, to show how mistakes might occur between acquired syphilis in infancy and congenital syphilis, and the last three to show how congenital syphilis might be the source of the acquired form. Not one of these cases is intended as a corroboration of Colles' law. In fact, no attempt has been made on the part of Colles to demonstrate this law by enumerating any personal observations. Thus, having accomplished his task of describing the disease communicated by the infant to the nurse, and of establishing its specific nature, he winds up by once more mentioning the fact, "well deserving our attention," of the immunity of the mother. This is referred to altogether three times, apart from the two remarks already quoted-viz., twice when he introduces the subject (p. 285) and once in the concluding sentence of the chapter. The three references are as follows :-

1. "The following fact appears to me very deserving of notice. I have never seen or heard of a single instance in which a syphilitic infant (although its mouth be ulcerated) suckled by its own mother had produced ulcerations of her breasts; whereas very few instances have occurred where a syphilitic infant had not infected a strange hired wet-nurse, and who had been previously in good health."

2. "It is a curious fact that I have never witnessed nor ever heard of an instance in which a child deriving the infection of syphilis from its parents has caused an ulceration in the breast of its nother.'

3. "One facs well deserving our attention is this: that a child born of a mother who is without any obvious venerea symptoms, and which, without being exposed to any infection subsequent to its birth, shows this disease when a few weeks old, this child will infect the most healthy nurse, whether she suckle it or merely handle and dress it; and yet this child is never known to infect its own mother, even though she suckle it while it has venereal ulcers of the lips and tongue.'

Of these three different ways of stating Colles' law, that which I designate No. 1 is by far the most definite. It must be stated that Colles was well aware that the mother of a syphilitic child need not present, either before or after the birth of the child, a single symptom of syphilis (pp. 266268), and that in undoubted cases of congenital syphilis the most careful examination might reveal nothing except the history of previous disease in the father. Particular stress must be laid on this fact, as it has not been pointed ont by any of the writers on the subject. Therefore, the rule as formulated in No. 1 is the fullest and most precise expression of the fact known as Colles' law, and I am not aware that it has been formulated in a better or more concise manner by any subsequent writer. Almost the same may be said of No. 2. The difficalty arising from the interpretation of the words "its parents" is not real. Certainly "its parents" might mean both parents or either of them; but that the last interpretation is undoubtedly the correct one follows from the fact that, according to Colles, the child may derive syphilis from one or both parents (p. 286), and that the mother might to all appearance escape altogether (p. 266). The interpretation of any text must be given in conformity with the viewa of the writer on the entire subject, and, although $I$ am quite aware of the difficulty which the words "its parents" might present to a purely philological mind, the meaning is clear to any medical man who has read the whole of Colles' book. In the same spirit one has to read No.3. Here the words "who is without any obvious venereal symptoms" are open to attack, as the possibility of past syphilitic symptoms is not excluded. It must be admitted that the meaning here is less clear than might be desired, but in the face of the two former statements one has without doubt only to deal with a certain laxity of expression.

I have before quoted, under $(a)$, a remark of Colles', which also suffers from indefiniteness of expression even to $a$ greater degree than No. 3. That a child "infected by the mother" does not communicate the disease to her nipple is a truth which forms only part of Colles' $1 \mathrm{w}$, and cannot be considered as an adequate expression of its whole meaning. The phrase merely states the fact that 
as the motber is actualiy suffering from syphilis she cannot of course be reinfected. In the same way the remark (b) only says that a mother who had previously contracted sypbilis and transmitted the disease to her offispring cannot be reinfected by the latter. Neither of these remarks was made with reference to cases adduced for the purpose of proving Colles' law, as has been erroneously stated," and, although they illustrate part of it, they were not intended to express its full meaning. They merely show that the mother who has had at any time symptoms of syphilis does not contract a chancre of the nipple from her syphilitic child. The "remarkable" observation first made by Colles is that, "whilst wet-nurses not infrequently contract chancre in the nipple from nursing syphilitic infants, such accidents never happen to the infant's mother.'"11 That mothers might give birth to syphilitic infants without ever exhibiting in themselves any symptoms of syphilis was known to Colles. It is well to bear in mind that Colles' observations were not made to fit or support any particular theory. His work, the sole object of which was practical utility (p. viii), was writtento use his own words about another worker on the same subject-" by a man who had no particular theory or doctrine to support, who seems to have written for the mere purpose of stating facts, and recording an account of the propzgation of this afflicting disease" (p. 24). It may be doubted whether Colles fully realised the theoretical bearing of his law. Regarding those cases in which the mother remains free from symptoms, he says that they are "so strange and so difficult to explain that nothing short of actual observation could induce us to allow the fact" (p. 266). He does not even attempt their explanation, but, whatever their explanation may be, whatever conclusions may have to be drawn from them, he was aware of their existence. He simply stated them as facts of actual observation, just as he stated it as a fact of mere clinical experience that a syphilitic child nursed by its mother does not infect her. No better and more definite expression of this rule could be wished for than Colles' own words, quoted under No. 1, by which he introduces the subject ander discassion. It will be found that reference to this most conclusive expression of his law is either omitted by his detractors or has been misconstrued in a manner neither warranted by his words nor by his teaching in ganeral, while Diday ${ }^{12}$ in 1854 quoted the same words for the first time under the denomination of "Colles' law."

In order to discuss the different interpretations which have been given to Colles' words it seems best to record them in the same chronological order as they appeared in the controversy evoked by a paper by Behrend.13 He first questions whether Colles really meant what is now understood as the law bearing his name. His whole argument is contained in the following sentence: "Moreover, up to the most recent date all the authors who reproduce the above rule formulated by Colles have not noticed that its framer, in corroboration of it, communicates the history of a case, and mentions expressly that two years before he had attended the father as well as the mother of the child for secondary syphilitic ulcerations, and that he does not speak about mothers who never showed a symptom of manifest syphilis, but only of those who had no visible (sichtbare) venereal symptoms, and who consequently (mithin) had latent syphilis." Behrend, therefore, concedes to Colles only the authorship of that part of the law which says that a mother who has had syphilis is not liable to be infected by suckling her child, while he attributes to Baumès the other part which says that the mother who has apparently escaped syphilis is not infected by the child to which syphilis has been transmitted from the father through her. To have united these two parts into one law, which says that a child suffering from hereditary syphilis does not infect its mother by suckling, is, according to Behrend, due to Diday, and he therefore considers the latter as the real author of what is commonly called Colles' law. ${ }^{14}$

In reference to the case alluded to by Behrend, and previously mentioned by me, I have to repeat that it was not given by Colles in corroboration of his law, but to show how 10 Baeumler (Handbuch der Syphilis, second edition, 1876, pp. 63 and
64) draws particular attention to the fact that Colles does not give a single case in nroof of the accuracy of what is now known as Colles' law, by Diday. 12 Loc. cit., p. 284.
Lon

13 Gustar Behrend: Zur Lehre von der Vererbung der Syphilis.

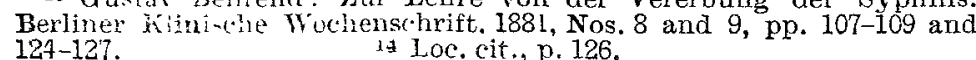

congenital syphilis in the child wight be the source of acquired syphilis in the servant. He only mentioned by the way the fact that the mother was not infected, while the servant was. The second part of Bebrend's sentence refers to No. 3. I have already mentioned that the words "without any obvious venereal symptoms" do not exclude the possibility of venereal symptoms in the past, but I fail to see how they can prove the existence of former symptoms. If this kind of argument is to hold good a general treatment of the human race by mercury would be indicated. Behrend quotes neither No. 1 nor No. 2, and therefore overlooks the fact that what he ascribes to Diday has already been said in identical words by Colles. Behrend's statements were accepted by $H$. and M. Zeissl, and incorporated in their wellknown text-book. ${ }^{15}$ To this Diday and Doyon ${ }^{16}$ replied by quoting No. 2, and remarking that they understood the words "without any obvious venereal symptoms" as meaning that the mothers had not had at any time any symptoms, while Behrend understood them to mean that there were no symptoms at the time of observation. Although the interpretation of Behrend is correct from a strictly grammatical point of view, I have pointed out before that in the light of No. 1 and No. 2 the interpretation of Diday alone is admissible, it being true to the sense if rot to the letter. He adds that Colles had been understood in the same sense by Ricord and Fournier. In 1883 Behrend's answer appeared ${ }^{17}$ under the title, "Is the so-called Colles' Law a Law or not?" He quotes in full the case to which he referred in his first communication, repeat ing his erronenns statement that Colles had given the case to prove his law, and he also repeats, without mentioning No. 1 , that the equivocal words in No. 3 point to present and not to past symptoms. His attention being drawn by Diday to No. 2 , he contends that the words "its parents" must be understood by everyone as both parents, and that this was meant by Colles. As shown above, the words might be understood as meaning either both parents or one of them, but they must be understood in the latter sense for the two reasons already given-viz., that Colles states himself that the child may derive the disease from one or both parents, and that he was aware of the cases in which the mother apparently escapes. Behrend winds up by repeating that, in adding the "additional" thesis of Baumès to the "original " thesis of Colles, Diday formulated what is wrongly called Colles' law. Behrend's reply was followed directly by an article from Diday and Doyan ${ }^{18}$ entitled "The Letter and the Spirit of Colles' Law." The writer insist upon the fact that not one of Colles' cases is intended as a proof of his law; that the meaning of the words "its parents" in No. 2 is not to be interpreted in the sense in which Behrend understands them; and that if they are properly understood as signifying "either of them," Colles' statement quoted under No. 2 is identical with the law formulated by Diday. Here the controversy between Behrend and Diday ends. It thus appears that Colles' most precise expression of his law No. 1 was never adduced on either side; that No. 2 , misinterpreted by Behrend, was considered to be identical by Diday with his own enunciation of the same law ; and also that the purpose for which Colles published his cases being misunderstood by Behrend, their importance and bearing were not rightly estimated by him. A remarkable feature of this discussion is that it was Didayto whom Behrend gives credit for having rightly under stood and best formulated what is meant by Colles' law, and to whom be consequently grants its authorshipwho, finding bis views unmistakably expressed by Colles, first introduced the expression, "Colles' law." He twice gracefully declines the honour which has been thrust upon him, thus vindicating Colles' xights, and protecting himself against "his friends." A short review of Behrend and Diday's papers was given by Michelson. ${ }^{19}$ He contents himself with merely stating the case without taking any side, but he expresses his astonishment that Diday declines the honour offered to him by Behrend. One might have expected that Diday's definite declaration would have put an end to this controversy, settling it in Colles' favour. This expecta. tion was not realised, however, for a paper was published in

\section{Lehrbuch der Syphilis, fourth edition, Stuttgart, 1882}

16 Annales de Dermatologie et de Syphiligraphie, 1882, vol.

pp. $288-298$

Der soi-disant Loi de Colles, est-elle une Loi ou non? Annales de Dermatologie et de Syphiligraphie, 1883, vol. iv., pp. 71-78.

Dermatologie is Linna's Rlonatshefte für Practische Dermatologie, vol. ii., p. 232. IIanthurg, 1883. 
1889 by M. Morel-Lavallée, ${ }^{20}$ who, under the advice of Foarnier, once more undertook to examine the merits of the contradictory statements previously made. Not a single argument that had not been previously adduced by Behrend was brought forward by M. Morel-Lavallée to strengthen his assertions, nor has one of the old arguments been shown in a different or a more convincing light. He does not dispute, as Behrend did, that the words "its parents" might be interpreted as " either parent," but this interpretation he considers to be "slightly forced." He again lays the whole stress upon the two quotations (a) and (b), which to him contain the "striking and blinding proofs" that Colles never meant to speak of cases where the father was syphilitic and the mother healthy. Of these cases, however, Colles did speak ; in fact, he particularly drew attention to them on pages 266 to 269 , he was well acquainted with their recurrence, and his teaching was that the hereditary syphilis of the child involves no danger to the nursing mother. M. Morel-Lavallée again adduces the same two cases of Colles, of which one was given to prove the infectiousness of the hereditary disease and the other to show how it might be mimicked by the acquired form. Both these cases exemplify that part of Colles' law which is explained by the unity of the two different forms of syphilis. Therefore, the remarks attached to them only refer to these individual cases, and cannot be quoted as the full expression of Colles' law. Under No. 1 No. 2, and No. 3 I have given above the three different ways in which this law is presented in its entirety in Colles' book, while $(a)$ and $(b)$ only represent its more restricted truth. M. Morel-Lavallée founds his argument on these casual remarks, and by generalisation he tries to throw doubt on the most definite statements made by Colles; but while he does not strengthen Behrend's case by adducing anything useful in argument or fact, he proceeds to weaken Colles' case by such tactics of interpretation that I cannot allow them to pass unexamined. The words "the most healthy nurse" furnish the basis for the following remarks - viz., that what Colles considered as the surprising feature was the fact of the healthy nurse being infected, and not the fact of the mother escaping infection and that Colles would have been less surprised to see the nurse contract a chancre of the nipple if she had been infected before - in fact, he would have expected the healthy nurse to escape and the syphilitic mother to be reinfected. According to M. Morel-Lavallée, Colles was under the idea that the syphilitic infection diminishes the resistance of the constitution, and therefore increases the predisposition to reinfection-that, in fact, a healthy person, and still more a "most healthy" person, was less liable to be infected than a person already affected with the disease. But there is not a single word in the whole of Colles' book to bear out what are given here as his views, nor does M. Morel-Lavallée, while he faces the "danger of further diminishing Colles' merit," even attempt to adduce a reason for his supposition. Let M. Morel-Lavallée re-read more than the few pages of Colles book which refer to the suckling of syphilitic children, and he will certainly find that even the few pages in question were written to prove the identity of acquired and con genital syphilis. He will also find that the negative results of inoculation experiments made with the syphilitic virus from one affected part into other parts of the same body were known to Colles. The meaning of the words " the most healthy nurse" appears most obvious-i.e., a nurse who never had any trace of specific disease, about whom, there fore, no doubt could exist that the disease was contracted from the infant, and not from any other source. M. MorelLavallée detects the same error in No. 1, where Colles says that "very few instances have occurred where a syphilitic infant had not infected a strange hired wet-nurse and who had previously been in good health." M. Morel-Lavallée exclaims : "This is always the same turn of thought; if the nurse had been tainted previously, Colles, it seems, would have been less surprised to see her (re)infected than to see her contaminated, having previously enjoyed good health.' How else, or in what plainer words, conld Colles have said what he wished to say-viz., that the nurse up to the time of infection by the child was healthy and free from syphilitic infection, and that therefore the origin of the infection could be established beyond doubt?

As the indefatigable champion of Colles' priority Diday ${ }^{21}$

20 Affaire Colles-Baumès. L'Union Médicale, troisième série, vol. xlvii., pp. $410-418$

21 Diday et Doyan: Une Enquête sur la Paternité: Colles? Baumès? L'Union Médicale, 1889, pp. 576-579. appeared again with a paper called "An Inquiry into Paternity : Colles? Baumès?" He rightly refers the reader to his former articles and the arguments adduced therein against Behrend, of which not one has been invalidated by M. Morel-Lavallée, and he again points out that his own formulation of Colles' law, which has been generally recognised as a correct and coruplete one, is identical with that of Colles. To this MI. Morel-Lavallée replies in a letter, ${ }^{22}$ in which he says that he withdraws from the discussion, although still conserving his opinion, because the whole question is one of translation and interpretation of an Finglish text, a matter on which a man ignorant of the subject of syphilis could give an opinion if he knew English sufficiently well. Still, he mentions that fournier agrees with him. Why quote Fournier if the opinion of a syphilograph is not necessary and of less value than that of an English scholar? I fully agree with M. Morel-Lavallée that a sufficient knowledge of English is all that is necessary to understand the meaning of Colles' words, and I trust that they will be understood in the future in the same sense which led M. Diday to affix Colles' name to the remarkable law first pointed out by him.

As regards Baumès, M. Morel-Lavallée adopts Bebrend's view that what since 1854 had been understood under the name of Colles' law consists of two parts-viz., one part pronounced by Colles and the other by Baumès-and that these two parts were first united into one law by Diday. If it were true that Baumès had introduced a fact not observed by Colles, which has to be added to Colles' observations in order to establish Colles' law, why replace Colles' name by that of Baumès and not by that of Diday? According to Behrend and Morel-Lavallée, Diday first enunciated in an unmistakable and precise form what was wrongly called Colles' law, though called so by Diday himself ; Behrend, therefore, consistently claims for Diday the authorship of Colles' law, restricting Baumès' merit to the "additional" thesis. M. Morel-Lavallé, on the other hand, in contradiction to his own statements, replaces the name of Baumèz for that of Colles, although either of them, according to him, originated only part of the latter's law. 'To this inconsistency he might. have been driven by the awkward position of otherwise having to give to the law a name the bearer of which declines. its authorship. It has fartber been argued in favour of Baumès that, while Colles did not support his law by detailed facts, Baumès did so; but on looking at the two observations which the latter relates (two mothers, one suckling five, the other two children, without being infected) it is found that in not one of the infants was the mouth affected, although they showed other signs of hereditary syphilis. Therefore, these cases do not fulfil the principal condition which every case of this kind has to meet, and which has been repeatedly insisted upon by Colles. As they do not even show that the possibility of a local infection was given, they cannot demonstrate the immunity of the mothers. Here I may mention an interesting fact communicated by Diday. ${ }^{23}$ In 1835 , two years before the publication. of Colles' book, Baumès visited England, bent on studying the medical schools of our country. At this time the original ideas of Colles, already professed by him, must have been known, and it is not impossible that Baumès might have learned Colles' law either from his own lips or through those influenced by his teaching. Therefore, to call the law after Baumès is most obviously a misnomer and in direct opposition to the facts granted by those who are responsible for it. The law, if not called after Colles, might have been called after Diday ; but here the difficulty arose that Diday, knowing his indebtedness to Colles, disclaimed any share in the framing of the latter's law. Baumès is only the figurehead under which the unsuccessful attempt on Colles' rights were made.

I cannot look upon the whole question from as serious a national point of view as M. Morel-Lavallée, who talks of a restitution of scientific priority by England to France. ${ }^{24}$ Colles had no better advocate than the Frenchman Didar, and he had no greater detractor than the Frenchman Morel-Lavallée. I should not have entered into the discussion of this subjeet again had not the criticisms of M. Morel-Lavallée been repeated as historical truths in such text-books as Fournier's, Kaposi's, and Zeissl's, which, being widely read, have given, undeserved propagation to the most arbitrary dealing with definite historical facts.

Welbeck-street, $W$.

22 L'Union Médicale, 1889, p. 790 . Letter dated May 23rd 23 L'Union Médicale, 1889 , p. 79 . Letter dated cit., p. 418 . 